\title{
Multiplanar Computed Tomographic Analysis of Frontal Cells According to International Frontal Sinus Anatomy Classification and Their Relation to Frontal Sinusitis
}

This article was published in the following Dove Press journal:

Reports in Medical Imaging

\author{
Huu Kien Pham ${ }^{1,2}$ \\ Tai Thanh Tran ${ }^{2}$ \\ Thanh Van Nguyen ${ }^{2}$ \\ Truc Thanh Thai ${ }^{3}{ }^{3}$ \\ 'Department of Otolaryngology, University \\ of Medicine and Pharmacy at Ho Chi Minh \\ City, Ho Chi Minh City, Vietnam; \\ ${ }^{2}$ Department of Otolaryngology - Head \\ and Neck Surgery, University Medical \\ Center, Ho Chi Minh City, Vietnam; \\ ${ }^{3}$ Department of Medical Statistics and \\ Informatics, University of Medicine and \\ Pharmacy at Ho Chi Minh City, Ho Chi \\ Minh City, Vietnam
}

Background: This study explored the prevalence of frontal cells and the relationship between different types of frontal cells classified using the International Frontal Sinus Anatomy Classification (IFAC) and frontal sinusitis.

Methods: A retrospective cross-sectional study was conducted with $1006 \mathrm{CT}$ scans of paranasal sinuses. Identification of frontal sinus cells was based on IFAC. The scans were classified into no frontal sinusitis, frontal sinusitis, isolated frontal sinusitis, no sinusitis.

Results: Agger nasi cells were the most common (91.9\%). The prevalence of supra agger cell (SAC) was $28.7 \%$, while the supra agger frontal cell (SAFC) was only $15.8 \%$, the supra bulla cell (SBC) was $59.7 \%$, the supra bulla frontal cell (SBFC) was $25.8 \%$. Supra orbital ethmoid cell (SOEC) and frontal septal cell (FSC) were identified in $6.9 \%$ and $14.3 \%$ of the cases, respectively. Patients with SAFCs and SBFCs were significantly more likely to develop frontal sinusitis (Odds Ratio (OR)=1.78, 95\% confidence interval (CI) 1.24-2.56 and $\mathrm{OR}=2.70,95 \%$ CI 1.98-3.66). Isolated frontal sinusitis was found in 10 scans and was associated with the presence of SAC (OR=3.76, 95\% CI 1.02-13.90).

Conclusion: In Vietnamese adult patients, frontal cells based on IFAC were prevalent and were associated with frontal sinusitis development, including isolated frontal sinusitis.

Keywords: International Frontal Sinus Anatomy Classification, frontal sinusitis, frontal cells, multiplanar computed tomographic analysis

\section{Introduction}

Among patients with frontal sinusitis, there is a high level of treatment failure using internal medication, possibly due to the complexity of frontal recess and the presence of frontal cells. ${ }^{1-3}$ The frontal recess is a complex space with an approximately inverted funnel shape whose apex is at the frontal ostium. In the frontal recess, multiple anterior ethmoid cells can be pneumatized. The complexity of the frontal recess and the risk of injury to the orbital and skull base during frontal sinus surgery are practical challenges even for experienced surgeons. Moreover, when performing endoscopic frontal sinus surgery, failure to remove frontal cells is among the most common causes of narrow frontal recess and frontal sinusitis recurrence. ${ }^{1}$ In a study by Otto and DelGaudio among patients with revision frontal recesses, $74 \%$ were found to have retain frontoethmoidal cells. ${ }^{3}$
Correspondence: Truc Thanh Thai Department of Medical Statistics and Informatics, University of Medicine and Pharmacy at Ho Chi Minh City, 217 Hong Bang Street, District 5, Ho Chi Minh City, Vietnam

Tel +8490838I 266

Email thaithanhtruc@ump.edu.vn 
Therefore, understanding the frontal cells can assist surgeons in conducting effective treatments for frontal sinusitis. In 1995, Kuhn classified the cells seen in the frontal recess and frontal sinus, but the International Frontal Sinus Anatomy Classification (IFAC) published in 2016 has been believed as an easier and more user-friendly approach to classify these cells. According to IFAC, three main types of cells exist in frontal recess, including cells that push the frontal sinus drainage pathway (FSDP) medially, posterior, anteriorly and laterally. ${ }^{4}$ The IFAC describes in detail the number and position of frontal cells and how these cells influence the frontal drainage pathway which is helpful in frontal endoscopic sinus surgery. This classification has been proved to be reliable. For example, Villarreal et al reported that IFAC has high level of test-retest reliability and inter-rater reliability with substantial to nearly perfect agreement among different rhinologists using IFAC at different points of time. ${ }^{5}$

To explore the frontal recess cells, Computed Tomography (CT) has been recommended due to its convenience and accuracy. The development of this technique, particularly the availability of triplanar CT images, has changed the view of surgical anatomy in the frontal recess. CT can assist to view the cells in frontal recess of the coronal, parasagittal, and axial reconstruction. Compared to coronal images alone, the three-dimensional information of the frontal recess is significantly enhanced by using both coronal and parasagittal reconstructed images. This results in significant effectiveness in planning frontal recess surgery. ${ }^{6} \mathrm{CT}$ provides an operational roadmap and thus improves the surgeon's perceptions in an attempt to decrease complications of endoscopic frontal sinus surgery. ${ }^{6}$

Many studies have assessed the correlation between frontal cells such as anterior frontoethmoidal cells (ANCs, FCs types 1-4), posterior cells (SBCs, FBCs, SOECs) and the development of frontal sinusitis. ${ }^{7-11}$ However, these studies used the classification described in 1994 by Bent and Kuhn which might have low level of reliability to identify specific frontal sinus cells. Although the IFAC has been shown to be superior to Kuhn classification in identifying and classifying frontal cells, only a few studies have been conducted using the IFAC to estimate the prevalence of frontal cells in patients with non-diseased sinuses. ${ }^{5,12,13}$ To date, there has been no study using the IFAC among patients with frontal sinusitis and isolated frontal sinusitis. ${ }^{5,13}$ In Vietnam, Tran et al analyzed frontal sinus drainage pathway types in relation to frontal cells (by the IFAC) using the Scopis Building
Block software and showed predominantly medial anteromedial drainage frontal drainage pathways in connection with these frontal cells. However, Tran et al 's study did not include patients with frontal sinusitis. ${ }^{12}$

To date, no research on the effect of frontal cells using the IFAC on frontal sinusitis has been reported. Therefore, we conducted this study to explore the prevalence of frontal cells and the relationship between different types of frontal cells classified using the IFAC and frontal sinusitis in patients with and without frontal sinusitis. We also examined the association between the presence of frontal cells and isolated frontal sinusitis.

\section{Materials and Methods Settings and Participants}

This retrospective cross-sectional study was conducted at the Department of Otorhinolaryngology, University Medical Center (UMC) in Ho Chi Minh City Vietnam, a major teaching and referral center for the country. UMC has nearly 8000 daily outpatient visits, of which about 500 patients visit otorhinolaryngology clinic. The sample size for this study was based on estimating the prevalence of frontal cells. Given the prevalence of Agger nasi cell of up to $90 \%$ in previous studies, ${ }^{2,10,12-14}$ type one error rate of 0.05 and marginal error of 0.03 , at least 385 patients were needed. We reviewed and recruited all 506 consecutive outpatients from the hospital medical records who had CT scans of the paranasal sinuses regardless of CT scan indications from January 2018 to March 2019. Exclusion criteria included age $<18$ years, previous sinus surgery, sinonasal malignancy, maxillofacial fracture, sinonasal polyposis and CT images inadequate triplanar reconstruction (axial, coronal and sagittal). All procedures in this study were approved by the Ethics Committee at the University of Medicine and Pharmacy at Ho Chi Minh City (approval number: 416/DHYD-HDDD).

\section{Procedures}

All patients were examined on a multi-slice Siemens CT scanner with overlapping axial cuts of $0.6 \mathrm{~mm}$ thickness and bone windows. The patients who satisfied our study criteria would have their information collected (age and gender). In a computer workstation axial, coronal and sagittal reconstructions were examined and used for analysis in the Picture Archive and Communication System (PACS). ${ }^{15}$ The cells were classified by the IFAC separately for the right and left sides at ipsilateral frontal recess. To minimize 
interpretation variability, each CT scan was analyzed independently by two ear-nose-throat (ENT) surgeons who underwent training about the IFAC. Any differences in evaluations were resolved by consensus in the presence of a rhinologist with experience in frontal sinusitis treatment.

\section{Measurements}

All available CT scan slides from recruited patients were categorized into two major groups including frontal sinusitis and no frontal sinusitis. Frontal sinusitis was defined as mucosal thickness of more than $3 \mathrm{~mm}$ involving the entire frontal sinus or its dependent portions. ${ }^{10}$ Besides, isolated frontal sinusitis and no sinusitis were also determined. Isolated frontal sinusitis was defined as a frontal sinus disorder associated with secondary obstruction or inflammatory modifications confined to the frontal recess. ${ }^{16}$

The type of the frontal cells were determined by magnification and appropriate window setting of coronals, axial and sagittal sections according to the criteria defined by the IFAC. These cells included ANCs (agger nasi cells) (see Figure 1A and B), SACs (Supra agger cells) (see Figure 1B), SAFCs (supra agger frontal cells) (see Figure 1A), SBCs (supra bulla cells) (see Figure 1C), SBFCs (supra bulla frontal cells) (see Figure 1C), SOECs (supraorbital ethmoid cells) and FSCs (frontal septal cells) (see Figure 1D). For example, identification of SACs was anterolateral ethmoid cell above the Agger nasi cell and did not pneumatize into the frontal sinus. Clinical history information was not required for the IFAC and thus was not recorded in this study.

\section{Data Analysis}

Descriptive statistics were used including mean, standard deviation for quantitative data and frequency, percentage for qualitative data. To compare the distribution of age and sex between those with and without frontal sinusitis, we used $t$-test and Chi-square tests when appropriate. Logistic regression was used to identify the association between the presence of different types of frontal cells and frontal sinusitis. The predictor variables were ANCs, SACs, SAFCs, SBCs, SBFCs, SOECs and FSCs. This analysis was also adjusted

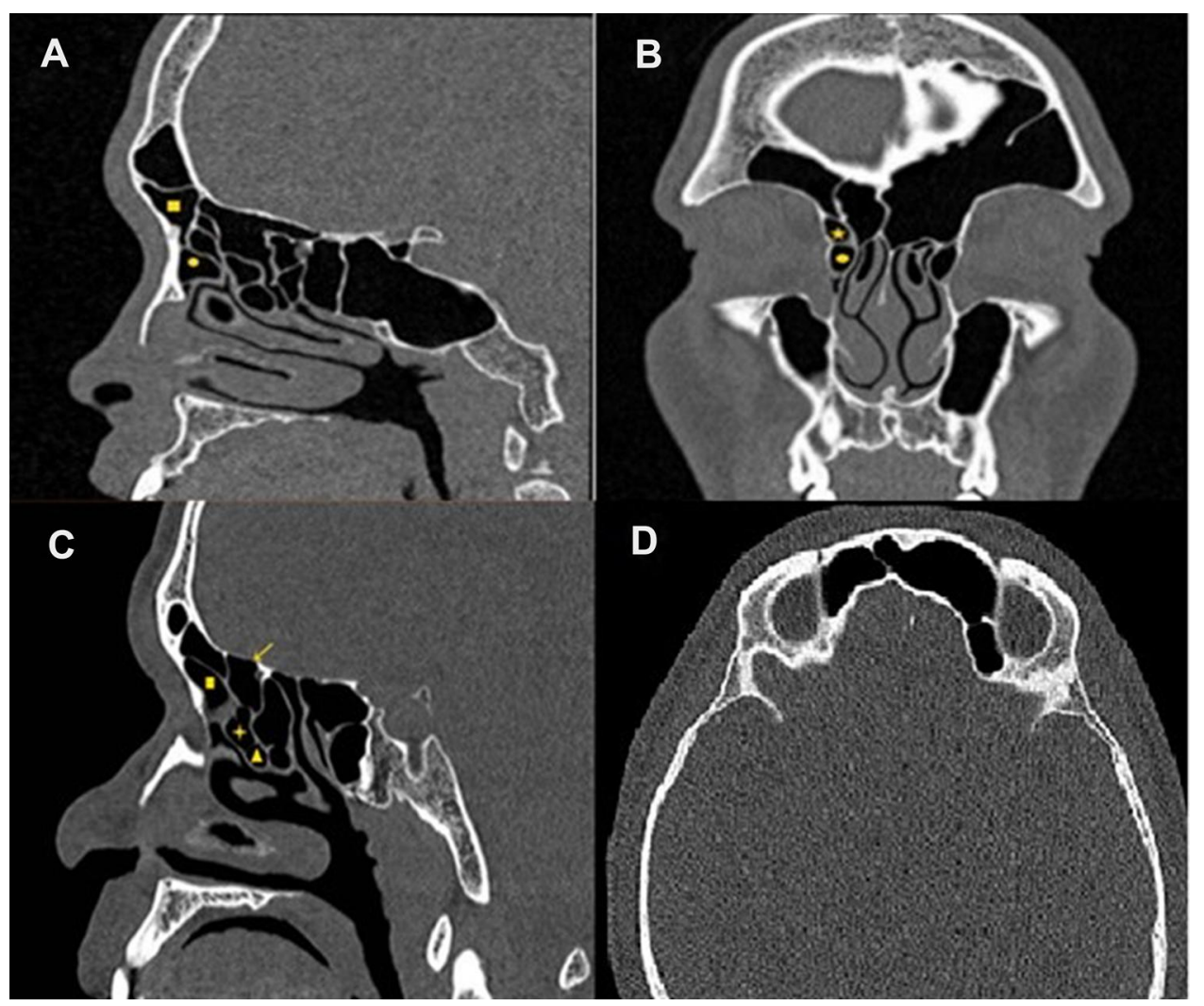

Figure I Computed tomography (CT) of paranasal sinuses showing identification of frontal recess cells based on International Frontal Sinus Anatomy Classification. (A) The sagittal computed tomography (CT) image shows a supra agger frontal cell - SAFC (filled square) above the agger nasi cell - ANC (filled circle) and extends into the frontal sinus; (B) A supra agger cell (filled star) is seen above the ANC (filled circle), a frontal septal cell (FSC) (filled diamond) located in the interfrontal sinus septum on the coronal CT image; (C) The sagittal CT image illustrates a supra bulla cell (SBC) (indicated by +), which is above the ethmoid bulla (EB) (filled triangle), a supra bulla frontal cell (SBFC) (solid arrow) pneumatizes along the skull base; (D) The supraorbital ethmoid cell (SOEC) (asterisk) pneumatizes over the orbit and around the anterior ethmoid artery (axial CT image). 
for age and sex. Type 1 error was set at 0.05. All data analysis was carried out using SPSS version 22.

\section{Results}

There were 1012 sides of paranasal sinuses CT scans with rhinosinusitis (no nasal polyps) and without rhinosinusitis among 506 patients. Six sides were excluded due to the absence of frontal sinuses which resulted in 1006 sides included in the analysis. The majority of patients were females $(52.1 \%)$ with a mean age of $41.0(\mathrm{SD}=13.5)$, ranging from 18 to 91 years old. Nearly one fourth of all CT scans indicated frontal sinusitis and $4 \%$ of which $(n=10)$ were isolated frontal sinus. There was no significant difference in age and sex between CT scans with and without frontal sinusitis; between isolated frontal sinusitis and no sinusitis (see Table 1). Based on the classification of IFAC, ANCs were the most prevalent (91.9\%, 925 sides) among anteriorly based cells, followed by SACs (28.7\%, 289 sides) and SAFCs (15.8\%, 159 sides) (see Figure 2). For posteriorly based cells, SBCs was the most dominant (59.7\%, 601 sides), followed by SBFCs $(25.8 \%, 260$ sides) and SOECs $(6.9 \%$, 69 sides) (see Figure 2). The medially based cells (ie, FSCs) were found in $14.3 \%$ (144 sides) of CT scans (see Figure 2).

We identified $24.8 \%$ of patients with frontal sinusitis on sinus CT. Patients with SAFCs and SBFCs had significantly higher odds of having frontal sinusitis with $\mathrm{OR}=1.78$, 95\% CI 1.24-2.56 and $\mathrm{OR}=2.70,95 \%$ CI 1.98-3.66, respectively. These associations remained unchanged after adjusting for age and sex $(\mathrm{OR}=1.80$, 95\% CI 1.25-2.59 and $\mathrm{OR}=2.71$, 95\% CI 1.99-3.69). The presence of other frontal cells including ANCs, SACs, SBCs, SOECs and FSCs was not statistically associated with frontal sinusitis (see Table 2). Among patients with isolated frontal sinusitis and no sinusitis, the presence of SAC was positively associated with isolated frontal sinusitis with $(\mathrm{OR}=3.47,95 \%$ CI 0.96-12.54) and without adjustment for age and $\operatorname{sex}(\mathrm{OR}=3.76,95 \%$ CI $1.02-13.90)$ (see Table 3).

\section{Discussion}

The frontal recess surgery is often difficult due to the size of the recess relative to the instrumentation and also the acute angle required to reach this region. Frontal sinusotomy is still the most challenging and hardest part of endoscopic sinus surgery. Our study thus helps understand frontal sinusitis pathology and frontal recess cells. Based on the IFAC, we found that the frontal recess prevalence of SAFC and SBFC was high in patients with frontal sinusitis while SAC was found in patients with isolated frontal sinusitis.

Despite a larger sample size, the prevalence of frontal cells found in our study was similar to that reported in previous studies. $^{5,12,13}$ A high prevalence of ANC found in our study $(91.5 \%)$ was similar to previous studies by Sjogren et al (88.9\%), Choby et al (96.5\%). ${ }^{12,13}$ Regarding the presence of the remaining 2 cells in the anteriorly based cell group, we found that SAC had higher rate than SAFC (34.1\% compared to $13.7 \%$ ). The prevalence of SAC in our sample was similar to that of Choby et al (30\%) and Sjogren et al (29.5\%) while SAFC had lower rate. This difference might be attributed to racial factors such as being Asian in our study and Caucasian in the other studies. Posteriorly based cells include SBC, SBFC and SOEC, all of which have similar classification criteria between the IFAC and Kuhn's description. In our study, SBC cells were the most common type with $60 \%$ of the cases, which was similar to that reported by Choby at $72 \%$ and Sjogren at $55.8 \%$. The prevalence of SBFC cells was higher than SOEC (20.7\% compared to $6.3 \%)$. However, Choby et al reported opposite results with lower prevalence of SBFC (5.5\%) than SOEC (28.5\%).

Our study was among the limited studies using IFAC to identify the effect of frontal cells on frontal sinusitis. We

Table I Patients' Characteristics, Stratified by Frontal Sinusitis Status Using Computer Tomography

\begin{tabular}{|c|c|c|c|c|c|c|c|}
\hline & \multirow{2}{*}{$\begin{array}{c}\begin{array}{c}\text { Total } \\
(n=1006\end{array} \\
100 \%)\end{array}$} & \multicolumn{3}{|c|}{ Frontal Sinusitis } & \multicolumn{3}{|c|}{ Isolated Frontal Sinusitis } \\
\hline & & $\begin{array}{c}\text { No Frontal Sinusitis } \\
(\mathrm{n}=757,75.25 \%)\end{array}$ & $\begin{array}{l}\text { Frontal Sinusitis } \\
(n=249,24.75 \%)\end{array}$ & p value & $\begin{array}{c}\text { Isolated Frontal } \\
\text { Sinusitis }(n=10,1 \%)\end{array}$ & $\begin{array}{c}\text { No Sinusitis } \\
(n=398,39.56 \%)\end{array}$ & p value \\
\hline $\begin{array}{l}\text { Age (year), } \\
\text { Mean } \pm S D\end{array}$ & $41.0 \pm 13.6$ & $40.6 \pm 13.8$ & $42.4 \pm 12.7$ & 0.065 & $38.4 \pm 10.9$ & $39.3 \pm 13.3$ & 0.827 \\
\hline $\begin{array}{l}\text { Sex, n (\%) } \\
\text { Male } \\
\text { Female }\end{array}$ & $\begin{array}{l}482(47.9) \\
524(52.1)\end{array}$ & $\begin{array}{l}357(47.2) \\
400(52.8)\end{array}$ & $\begin{array}{l}125(50.2) \\
124(49.8)\end{array}$ & 0.405 & $\begin{array}{l}4(40.0) \\
6(60.0)\end{array}$ & $\begin{array}{l}183(46.0) \\
215(54.0)\end{array}$ & 0.708 \\
\hline
\end{tabular}




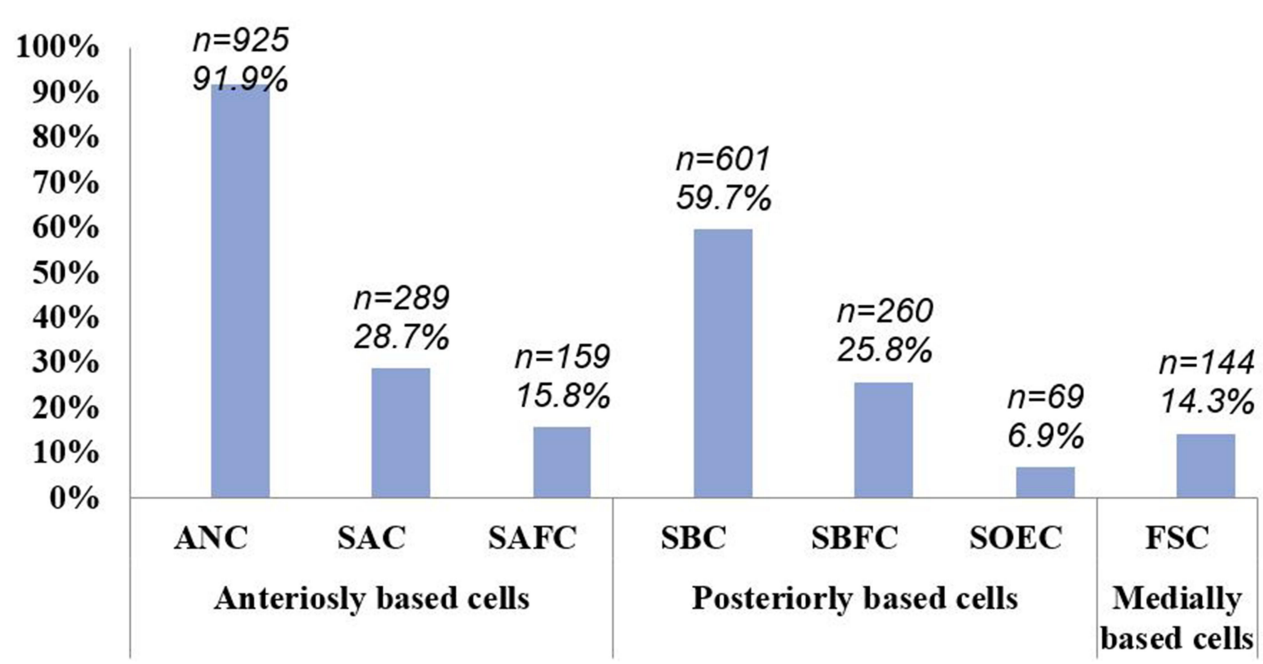

Figure 2 The prevalence of frontal cell types.

Abbreviations: ANC, agger nasi cell; SAC, supra agger cell; SAFC, supra agger frontal cell; SBC, supra bulla cell; SBFC, supra bulla frontal cell; SOEC, supra orbital ethmoid cell; FSC, frontal septal cel.

found that the presence of SAFC and SBFC was associated with the development of frontal sinus. The frontal sinus is embryologically derived from pneumatization of the ethmoid, frontal sinus outflow is thus influenced and defined by the degree of pneumatization of the ethmoid labyrinth. In our study, SAFCs and SBFCs had many affects on the frontal sinus outflow. SAFC is an anterolateral ethmoid cell that extends into the frontal sinus and

Table 2 The Associations Between Frontal Cells Identified by IFAC and Frontal Sinusitis

\begin{tabular}{|c|c|c|c|c|c|c|c|c|}
\hline \multirow[t]{2}{*}{ Cell Types } & \multirow{2}{*}{$\begin{array}{c}\text { Frontal Sinusitis } \\
\mathbf{N}=249 \text { n (\%) }\end{array}$} & \multirow{2}{*}{$\begin{array}{c}\text { No Frontal Sinusitis } \\
\mathrm{N}=757 \text { n (\%) }\end{array}$} & \multicolumn{3}{|c|}{ Crude } & \multicolumn{3}{|c|}{ Adjusted } \\
\hline & & & OR & $95 \% \mathrm{Cl}$ & p value & OR & 95\% Cl & p value \\
\hline ANC & $232(99.2)$ & 737 (9I.5) & 1.49 & $0.83-2.66$ & 0.175 & 3.40 & $0.79-14.67$ & 0.101 \\
\hline SAC & 61 (24.5) & $258(34.1)$ & 0.75 & $0.54-1.04$ & 0.089 & 0.77 & $0.55-1.01$ & 0.118 \\
\hline SAFC & $55(22.1)$ & 104 (I3.7) & 1.78 & $1.24-2.56$ & 0.002 & 1.80 & $1.25-2.59$ & 0.002 \\
\hline SBC & I 47 (59.I) & $454(60.0)$ & 1.03 & $0.77-1.38$ & 0.835 & 1.04 & $0.7|-| .52$ & 0.855 \\
\hline SBFC & $103(4 \mid .4)$ & 157 (20.7) & 2.70 & $1.98-3.66$ & $<0.001$ & 2.71 & $1.99-3.69$ & $<0.001$ \\
\hline SOEC & $21(8.4)$ & $48(6.3)$ & 1.36 & $0.80-2.32$ & 0.257 & 1.36 & $0.80-2.33$ & 0.257 \\
\hline FSC & $33(13.2)$ & III (I4.7) & 0.89 & $0.58-1.35$ & 0.582 & 0.90 & $0.59-1.37$ & 0.629 \\
\hline
\end{tabular}

Abbreviations: ANC, agger nasi cell; SAC, supra agger cell; SAFC, supra agger frontal cell; SBC, supra bulla cell; SBFC, supra bulla frontal cell; SOEC, supra orbital ethmoid cell; FSC, frontal septal cell.

Table 3 The Associations Between Frontal Cells Identified by IFAC and Isolated Frontal Sinusitis

\begin{tabular}{|l|c|c|c|c|c|c|c|c|}
\hline \multirow{2}{*}{ Cell Types } & IFS & NS & \multicolumn{3}{|c|}{ Crude } & \multicolumn{3}{|c|}{ Adjusted } \\
\cline { 2 - 8 } & N=10 n (\%) & N=398 n (\%) & OR & $95 \%$ CI & P & OR & $95 \%$ CI & P \\
\hline ANC & $10(100)$ & $367(92.2)$ & 1.03 & $1.01-1.05$ & 0.359 & - & - & $1.02-13.90$ \\
SAC & $6(60.0)$ & $120(30.2)$ & 3.48 & $0.96-12.54$ & 0.044 & 3.76 & 0.047 \\
SAFC & $2(20.0)$ & $59(14.8)$ & 1.44 & $0.29-6.93$ & 0.650 & 1.45 & $0.30-7.03$ & 0.641 \\
SBC & $5(50.0)$ & $246(61.8)$ & 0.62 & $0.18-2.17$ & 0.448 & 0.56 & $0.16-2.14$ & 0.413 \\
SBFC & $4(40.0)$ & $82(20.6)$ & 2.57 & $0.71-9.32$ & 0.137 & 2.65 & $0.70-10.1$ & 0.150 \\
SOEC & $1(10.0)$ & $35(8.8)$ & 1.15 & $0.14-9.36$ & 0.894 & 1.90 & $0.21-17.37$ & 0.572 \\
FSC & $2(20.0)$ & $59(14.8)$ & 1.44 & $0.30-6.93$ & 0.650 & 1.61 & $0.32-8.21$ & 0.566 \\
\hline
\end{tabular}

Abbreviations: ANC, agger nasi cell; SAC, supra agger cell; SAFC, supra agger frontal cell; SBC, Supra Bulla Cell; SBFC, supra bulla frontal cell; SOEC, supra orbital ethmoid cell; FSC, frontal septal cell; IFS, isolated frontal sinusitis; NS, no sinusitis. 
SBFC originates in the supra bulla region and pneumatizes along the skull base into the posterior region of the frontal sinus. ${ }^{4}$ These cells through pneumatically frontal ostium, which is the narrowest part of frontal sinus drainage pathway, may trigger further narrowing of the frontal sinus drainage pathway. In a study in Taiwan, Lien et al examined 384 sides to classify frontal cells using Kuhn's criteria and found that the frontal sinus drainage pathway of posterior cells such as SBC, FBC, and SOEC (SBC, SBFC and SOEC according to the IFAC) could be associated with frontal sinusitis growth. ${ }^{10}$ A similar study by Meyer et al in $768 \mathrm{CT}$ sinus revealed that higher incidence of frontal sinusitis was seen with FCs 3 and 4 (IFAC's similar SAFC). ${ }^{11}$ Our study showed that frontal sinusitis was correlated with the presence of SAFC which are located anterior cells as well as SBFC (in posterior cells). In contrast, DelGaudio et al reported that the presence of frontal cells (SAC and SAFC comparable to the IFAC) was not correlated with frontal sinusitis. ${ }^{8}$ Our findings revealed the need to remove $\mathrm{SAFB}$ and $\mathrm{SBFC}$ to prevent the recurrent frontal sinusitis.

Isolated frontal sinusitis rarely happens and very few studies explored the prevalence of frontal cells and pathophysiology of isolated frontal sinusitis. ${ }^{16,17}$ Our study showed that most types of frontal cells appeared to be similar in frontal sinusitis group and that the presence of SACs was correlated with isolated frontal sinusitis. Isolated frontal sinusitis is not common and may be correlated with a structural abnormality or lesions of the frontal sinus opening and surrounding structures. ${ }^{17}$ In a study among 15 patients with isolated frontal sinus Jun-Feng Ji revealed that type 2 and type 3 frontal bulla cell (SAC and SAFC) were critical factors in frontal recess obstruction. ${ }^{17}$ SACs are anterolateral ethmoidal cells, located above the agger (not pneumatized into the frontal sinus). Although SACs are not pneumatized into the frontal sinus through ostium frontal, they push the frontal sinus drainage pathway posteriorly. ${ }^{4}$ The more SACs and other surrounded cells exist on the drainage frontal sinus pathway the frontal recess is narrower.

Our study has several limitations. Frontal sinusitis is caused by multiple factors, including anatomic variations, mucosal inflammation, sinonasal polyposis, systemic patients factors (immunosuppression, autoimmune disease, allergy, diabetes and a host of others) and previous treatment (antibiotic, steroids, etc.). ${ }^{8,18}$ Therefore, in this study, we were unable to conclude whether the presence of frontal cells was more or less important factor leading to frontal sinusitis as compared to other factors. Moreover, due to unavailability of data, it is not clear from our study about the explanatory role of clinical information in the association between frontal cells and sinusitis. For example, it remains unclear whether there is difference in the number of frontal cells based on duration of frontal sinusitis. Additionally, although our study had the largest number of patients as compared to previous studies, we had relatively small number of isolated frontal sinusitis. These limitations indicated the need for further study involving more patients with isolated frontal sinusitis and study evaluating other clinical factors.

\section{Conclusions}

In Vietnamese adult patients, the frequencies of frontal cells based on IFAC were inconsistent to other studies. Two types of frontal cells extend into the frontal sinus (SAFC and SBFC) were associated with a significantly higher rate of frontal sinusitis development than other frontal cells. Although isolated frontal sinusitis is uncommon, this disease was significantly correlated with the presence of SAC. For successful endoscopic frontal sinus surgery, surgeons should use CT images to explore the frontal recess anatomy, especially the cells obstructing the natural draining pathway of the frontal sinus.

\section{Data Sharing Statement}

The data that support the findings of this study are available from the corresponding author upon reasonable request.

\section{Ethical Approval}

All procedures followed were approved and were in accordance with the ethical standards of the responsible committee on human experimentation (Ethics Committee at the University of Medicine and Pharmacy at Ho Chi Minh City; approval number: 416/DHYD-HDDD) and with the Helsinki Declaration of 1975, as revised in 2000. This study was based on the retrospective review of medical records when all patients had been discharged and thus the need for informed consent from each individual patient was waived by the Committee. All patient data were kept confidential in according to the Vietnam national standard.

\section{Acknowledgment}

We highly appreciate about the cooperation of Radiology Department at University Medical Center in Ho Chi Minh 
City and we would like to extend our gratitude to patients for providing us to conduct this study.

\section{Funding}

The authors received no specific funding for this study.

\section{Disclosure}

The authors declare no conflicts of interest for this work.

\section{References}

1. Thawley SE, Deddens AE. Transfrontal endoscopic management of frontal recess disease. Am J Rhinol. 1995;9(6):307-312. doi:10.2500/ 105065895781808748

2. Bradley DT, Kountakis SE. The role of agger nasi air cells in patients requiring revision endoscopic frontal sinus surgery. Otolaryngol Head Neck Surg. 2004;131(4):525-527. doi:10.1016/j.otohns.2004. 03.038

3. Otto KJ, DelGaudio JM. Operative findings in the frontal recess at time of revision surgery. Am J Otolaryngol. 2010;31(3):175-180. doi:10.1016/j.amjoto.2008.12.006

4. Wormald PJ, Hoseman W, Callejas C, et al. The International Frontal Sinus Anatomy Classification (IFAC) and Classification of the Extent of Endoscopic Frontal Sinus Surgery (EFSS). Int Forum Allergy Rhinol. 2016;6(7):677-696. doi:10.1002/alr.21738

5. Villarreal, R, Wrobel, BB, Macias-Valle, LF, et al. International assessment of inter- and intrarater reliability of the International Frontal Sinus Anatomy Classification system. Int Forum Allergy Rhinol. 2019;9:39-45. doi:10.1002/alr.22200.

6. Kew J, Rees GL, Close D, et al. Multiplanar reconstructed computed tomography images improves depiction and understanding of the anatomy of the frontal sinus and recess. Am J Rhinol. 2002;16(2):119-123. doi:10.1177/194589240201600209

7. Bent JP, Cuilty-Siller C, Kuhn FA. The Frontal Cell as a Cause of Frontal Sinus Obstruction. American Journal of Rhinology. 1994;8 (4): 185-192. doi:10.2500/105065894781874278
8. DelGaudio JM, Hudgins PA, Venkatraman G, Beningfield A Multiplanar computed tomographic analysis of frontal recess cells: effect on frontal isthmus size and frontal sinusitis. Arch Otolaryngol Head Neck Surg. 2005;131(3):230-235.

9. Kubota K, Takeno S, Hirakawa K. Frontal recess anatomy in Japanese subjects and its effect on the development of frontal sinusitis: computed tomography analysis. J Otolaryngol Head Neck Surg. 2015;44:21. doi:10.1186/s40463-015-0074-6

10. Lien CF, Weng -H-H, Chang Y-C, et al. Computed tomographic analysis of frontal recess anatomy and its effect on the development of frontal sinusitis. Laryngoscope. 2010;120(12):2521-2527. doi:10.1002/lary.20977

11. Meyer TK, Kocak M, Smith MM, et al. Coronal computed tomography analysis of frontal cells. Am J Rhinol. 2003;17(3):163-168. doi: $10.1177 / 194589240301700310$

12. Tran LV, Ngo NH, Psaltis AJ. A radiological study assessing the prevalence of frontal recess cells and the most common frontal sinus drainage pathways. Am J Rhinol Allergy. 2019;33(3):323-330. doi:10.1177/1945892419826228

13. Choby G, Thamboo A, Won T-B, et al. Computed tomography analysis of frontal cell prevalence according to the International Frontal Sinus Anatomy Classification. Int Forum Allergy Rhinol. 2018;8(7):825-830. doi:10.1002/alr.22105

14. Lee WT, Kuhn FA, Citardi MJ. 3D computed tomographic analysis of frontal recess anatomy in patients without frontal sinusitis. Otolaryngol Head Neck Surg. 2004;131(3):164-173. doi:10.1016/j. otohns.2004.04.012

15. Choplin RH, Boehme JM, Maynard CD. Picture archiving and communication systems: an overview. RadioGraphics. 1992;12 (1):127-129. doi:10.1148/radiographics.12.1.1734458

16. Landsberg R, Segev Y, Friedman M, et al. A targeted endoscopic approach to chronic isolated frontal sinusitis. Otolaryngol Head Neck Surg. 2006;134(1):28-32. doi:10.1016/j.otohns.2005.09.009

17. Ji JF, Cheng Y, Wang T-Y, et al. Isolated frontal sinusitis treated using an anterior-to-ethmoidal bulla surgical approach. Cell Biochem Biophys. 2014;70(2):1153-1157. doi:10.1007/s12013-014-0035-0

18. Han JK, Ghanem T, Lee B, et al. Various causes for frontal sinus obstruction. Am J Otolaryngol. 2009;30(2):80-82. doi:10.1016/j. amjoto.2008.02.009
Reports in Medical Imaging

\section{Publish your work in this journal}

Reports in Medical Imaging is an international, peer-reviewed, open access journal publishing original research, reports, reviews and commentaries on all areas of medical imaging. The manuscript management system is completely online and includes a very quick and fair peerreview system, which is all easy to use. Visit http://www.dovepress. com/testimonials.php to read real quotes from published authors. 